\title{
СМЫСЛ МОДЫ: ВЕРБАЛЬНАЯ И ВИЗУАЛЬНАЯ ЭСТЕТИЧЕСКАЯ КОММУНИКАЦИЯ
}

Аннотация. В статье исследуется понятие феномена моды в современной культуре, раскрывается философско-эстетическое понимание смысла моды, рассматривается смысл и значение понятий "эстетический опыт", "эстетическое познание", анализируются вербальный и визуальный уровни эстетического сообщения в моде. Исследуется, каким образом достигается эстетическое познание моды, как концептуализируется избыточность эстетических смыслов в эстетическом опыте субъекта. Рассматриваются основные философские концепции, затрагивающие проблематику работы, выявляются смысловые коды, передаваемые на невербальном и вербальном уровнях эстетической коммуникачии. В качестве методологической основы используется философско-эстетический модус теории коммуникации, философско-эстетический анализ феномена моды в разрезе вербальной и визуальной эстетической коммуникации.

Научная новизна заключается в использовании указанной методологии, которая является исключительно новаторской для подобного рода исследований, даётся подробная характеристика выявленных уровней коммуникации, рассматриваются имплицитные и эксплицитные уровни смыслов эстетических сообщений в современной индустрии моды. На визуальном уровне раскрываются такие формы и приёмы выразительности, как цвет, силуэт, композиция, ритм, орнамент, стилеобразование, эклектика, стилизация; анализ вербального уровня эстетической коммуникации опирается на риторику модных журналов и рекламных кампаний.

Ключевые слова: мода, смысловой код, эстетическая коммуникация, эстетический опыт, эстетическое познание, визуализация, вербализация, выразительность, стиль, игра.

Review. The article is devoted to the phenomenon of fashion in contemporary culture. In this research Guzha gives a philosophical and aesthetical definition of fashion, examines the meaning and importance of such terms as 'aesthetic experience' and 'aesthetic knowledge' and analyzes the verbal and visual levels of aesthetic communication in fashion. The author also studies the manners in which aesthetic perception of fashion is achieved and excessive aesthetic meanings are conceptualized in individual aesthetic experience. The author describes the main concepts on the matter and defines semantic codes transmitting aesthetic communication at nonverbal and verbal levels. The methodological basis of the research involves the philosophical-aesthetic modus of the communication theory, philosophical and aesthetic analysis of the fashion phenomenon from the point of view of verbal and visual aesthetic communication. The scientific novedlty of the research is caused by the fact that the author applies the aforesaid methodology, which is exclusively innovatory for such kind of research, provides a detailed description of the communication levels determined and views implicit and explicit levels of aesthetic messages in modern fashion industry. The following expressive kinds and means are described at the visual level: colour, silhouette, composition, rhythm, ornament, style making process, eclectic and stylization. The analysis of the verbal level of aesthetic communication focuses on the rhetoric of fashion magazines and advertising companies.

Key words: fashion, semantic code, aesthetic communication, aesthetic experience, aesthetic knowledge, visualization, verbalization, expressivity, style, play.

$\mathrm{T}$ ермин мода (французское «mode» или английское «fashion») происходит от латинского "modus" - мера, способ, эталон, образ, правило, предписание, качество, природа. Определений «моды» бесконечно много. Это и социальный механизм (Г. Зиммель), и меняющийся образ жизни (А. Смит), и игра (К.С. Шаров), и все существующие стили в одежде в данный момент времени (Холландер), и прихотливый обычай (словарь
Даля), и вечное возвращение нового (В. Беньямин), и ложное женское самосознание (Д. Филькенштейн), и даже мистифицированная сфера взаимоотношений жизни и одежды (Р. Барт).

Какими бы ни были частные определения моды, важно отметить два основных главенствующих понятия в научно-исследовательской литературе: мода в узком смысле слова - это определённые актуальные тенденции в дизайне одежды, 


\section{Философия и культура 11(95) • 2015}

меняющиеся каждый сезон (цвета, фасоны, силуэт и т.п.), и, в широком смысле, это некая логика, характеризующаяся исключительно принципом новизны ради самой этой новизны и регулирующая все сферы общественной жизни (например, мода на литературу, на образ жизни), начиная с конца XIX в., когда мода начала пониматься в современном нам смысле (с даты основания первого дома моды Чарльзом Вортом).

Смысл моды трактуется различными направлениями философской мысли дискуссионно и вариативно, опираясь, с одной стороны, на понимание того, что принимается в качестве исходного определения «смысла», с другой стороны, на то, как исследователями трактуется сам феномен моды. В настоящем исследовании под смыслом моды понимается мысленное, коннотативное содержание указанного явления, попытка раскрыть очевидные и скрытые, неявные идеи формирования модного пространства со всем калейдоскопом риторики, образов, стилей. Мода - явление иррациональное, связанное с эмоциональным восприятием её адепта; приятие или неприятие той или иной модной позиции базируется не на рациональном подсчёте, а на эстетическом опыте. Разумеется, адептами моды могут выступать не только отдельные личности, но и корпорации, маркетологи, руководители компаний фэшн-индустрии и др. В данной статье будут рассмотрены философско-эстетические основания феномена моды, хотя, конечно, исследования в области рыночных отношений не менее важны для понимания исследуемого явления и в должной степени изучаются смежными науками.

Эстетическое познание в культурной сфере достигается и измеряется средствами выразительности, которые представляют собой особого рода знаки, снятие которых происходит эмоциональными способами познания. Предпосылки для эстетического опыта в сфере моды создаются на основе избыточности визуальных и вербальных смыслов, задействованных в процессе эстетической коммуникации.

Эстетическое сообщение, как пишет У. Эко, это такое сообщение, которое «построено так, что оказывается неоднозначным и направлено на самое себя, т. е. стремится привлечь внимание адресата к тому, как оно построено» ${ }^{1}$. Эстетическое сообщение в феномене моды относится к двум способам выражения. Во-первых, это способ вербальной эстетической коммуникации в моде, который наделен двумя составляющими, такими как коннотатив-

Эко У. Отсутствующая структура. Введение в семиологию. СПб.: ТОО ТК «Петрополис», 1998. С. 79. ный (смысловой) и денотативный (характеризующий предметное значение) уровень. Во-вторых, это сообщение средствами визуальной эстетической коммуникации, который соотносится с материальными формами выразительности.

Эстетический опыт и чувство прекрасного в моде достигается за счёт избыточности, которая присутствует на всех уровнях её репрезентации. Избыточность представляет собой насыщенность какого-либо пространства коммуникативными эстетическими смыслами. У. Эко также отмечает это свойство сообщений эстетического познания. Как известно, из современных достижений информационной эстетики, чем выше избыточность и меньше сложность, тем больше красоты (формула выведена Биргхофом и усовершенствована Бензе). Современное пространство повседневности, окружающее человека моды весьма избыточно. Человек живёт в мире красоты и каждый сезон эта красота пополняется новыми эстетическими смыслами. Тот, кто вступает в мир моды, оказывается в особом мире желаемого, где возможно всё, благодаря игре символических и эстетических сил в условиях отсутствия любых ограничений и морали, где действует только закон стихии Моды.

К непосредственно эстетическому содержанию феномена моды можно отнести все символические конфигурации, которые образовались в этой сфере. Это и риторика модных рекламных компаний, журналов, и формообразование одежды и предметов интерьера и т.п.

Рассмотрим первый уровень эстетического знания, базирующемся на вербальной коммуникации. В моде парадоксальным образом происходит круговорот смыслов, порождая новые пути для эстетического опыта, и, как пишет Р. Барт, создавая тем самым особую ауру священных текстов: «текст Моды - это как бы властное слово того, кто знает все скрытое за смутной или отрывочной внешностью зримых форм; он представляет собой технику открытия незримого, и здесь можно даже усматривать в секуляризованной форме священную ауру дивинационных текстов» ${ }^{2}$. Подобного рода аура создаётся благодаря «волшебству» символических связей. В Моде можно выделить несколько десятков смыслов, которые и создают то эстетическое пространство, воспроизводящее базовые значения, относящиеся сегодня к непрофанному пониманию Моды. Значений объектов, к которым апеллирует модное слово только два, а именно внешний мир и

\footnotetext{
Барт Ролан. Система Моды: Статьи по семиотике культуры / Пер. с фр., вступ. ст. и сост. С.Н. Зенкина. М.: Изд-во им. Сабашниковых, 2003. С. 48.
} 
сама Мода. Соотношение смыслов моды и внешнего мира весьма произвольны и неоднозначны, чем создают огромное пространство для воображения. Никто не спорит, что туфли на высоком каблуке делают походку женщины более изысканной, но вот с тем, что шляпка создаёт молодость, так как открывает лоб, а с модным аксессуаром приходит весна, с точки зрения здравого смысла хочется подискутировать. Однако внутри Моды не существует никаких дискурсов, и если Она, Мода, так утвердила в своей «библии», модном журнале, то это последняя истина не подлежит сомнению. «Слово (журнал) завладевает объектами и, не меняя их материи, запечатлевает на них смысл, придаёт им знаковую жизнь; оно может и вновь отнять её у них, так что смысл нисходит на объект подобно благодати» 3 .

Что же касается второго вида значений в исследуемом феномене, а именно апелляции к самой Моде, то здесь, с точки зрения Барта, мы сталкиваемся с пустотным содержанием, однако на фоне такой концептуальной пустотности, по мнению автора, его денотативное содержание весьма богато, поскольку соотносится со скрытым содержанием, которое проявляется в некоем коллективном воображаемом, связанном с обобщённым личностным ощущением времени, предвкушением будущего и страстным желанием обновления.

Игра смыслов, как отмечалось выше, задаёт основания для эстетического опыта, но и также она меняет ощущение существования отдельных индивидов, которые активно воспринимают эстетические сообщения моды: «вовлекая в комбинаторику оригинальные единицы, [мода] делает возможным и утопическое представление о мире, где возможно всё - как уик-энд на Таити, так и строгая мягкость, благодаря [моде] смыслы одежды могут возникать из самых невообразимых горизонтов и обозначать её уникально-необратимые применения; тем самым одежда превращается в чистое событие <...> означаемое позволяет ощутить встречу с <..> насыщенным мгновением, <..> это отношение непосредственного переживания, хотя бы и воображаемого» ${ }^{4}$. Перед нами механизм бесконечно струящихся метафор, который каждый раз переигрывается, имея лишь единственный источник - пустое содержание «Мода». У Жана Бодрийяра читаем: «мода занимает необычайно привилегированное положение, оттого, что мир в ней полностью разрешается. Ускорение чистой дифференциальной игры означающих выступает в ней феерически ярко - феерическое головокружение

\footnotetext{
Там же. С. 99.

4 Там же. С. 237.
}

от утраты всякой референции» ${ }^{5}$. Как Бодрийяр, так и Барт, объясняют это особенностями современного общества, в котором культурные смыслы произвольны и в это же время рационально обоснованы.

Мода превращает одежду не в некое обязательное условие выживания (защита от холода, например), а в условие бесконечной возможности эстетического опыта: свитер для осенних вечеров; жакет, кожаные перчатки и твидовая кепка для прогулок по садам Тюильри; набивная ткань для победы на скачках. Все это: осенние вечера, прогулка по Тюильри, присутствие на скачках создаёт ореол волшебства, который умножается, даже мощно взрывается, благодаря эстетическому переживанию и воображению, даже в том случае, если вы просто купили твидовую кепку и не летали в Париж. «Одежда играет в одежду и тем самым опосредуется личностью, демонстрирует личность достаточно богатую, чтобы часто менять роли, в конце концов, трансформируя одежду, человек трансформирует и свою душу» 6 .

Мода - это не бессмысленная комбинаторика форм и фасонов, это сложное создание образов, несущих в себе как социальную нагрузку, отражающую актуальные стороны действительности, так и нечто от моделирования воображаемых миров, врывающихся в сознание человека и открывающих новое эстетическое пространство.

Второй уровень создания эстетических смыслов, названный нами визуальным, связан с материальным проявлением носителей модных ценностей и обеспечивается особыми средствами выразительности. Поскольку мода реализует свой потенциал наиболее многообразно и специфично в структуре одежды, то последняя будет рассмотрена в качестве базиса для характеристики выразительных форм моды и основных приёмов их использования. К подобного рода формам следует отнести такие элементы выразительности, как цвет, силуэт, композиция, ритм, орнамент. К основным же приёмам, или способам, используемым в индустрии моды и структурирующим вышеперечисленные компоненты создания модного образа, относятся такие, как стилеобразование, эклектика и стилизация.

Важное коммуникативное значение несут на себе задействованные в модном образе цвета. В древности цвета называли «божествами», деятели

\footnotetext{
Бодрийяр Ж. Символический обмен и смерть. 2-е изд. М.: Добросвет, КДУ, 2006. С. 169.

6 Барт Ролан. Система Моды: Статьи по семиотике культуры / Пер. с фр., вступ. ст. и сост. С.Н. Зенкина. М.: Изд-во им. Сабашниковых, 2003. С. 225.
} 


\section{Философия и культура 11(95) • 2015}

искусства соотносят их с «материальными состояниями души» или, к примеру, с «разрядами страстей». В науке, как отмечает исследователь психологии моды М. Килошенко, выделяют три способа воздействия цвета на человека: через рецепторы кожи, впитывающие энергию цвета; через зрительное восприятие, характеризующееся особенностями влияния определённого цвета на эмоции индивида; и характеризующийся воздействием на социальные группы, на поведение членов которых влияет цветовосприятие. В.В. Кандинский подразделяет воздействие цвета на физическое и психическое. Первое возникает тогда, «когда глаз очарован его [цвета] красотой и другими его свойствами. Зритель испытывает чувство удовлетворения, радости» ${ }^{7}$. Психическое воздействие отличается тем, что в нем «обнаруживается психическая сила краски, она вызывает душевную вибрацию. Так первоначальная элементарная физическая сила становится путем, на котором цвет доходит до души» ${ }^{8}$. Каждый цвет уникален; наделенный индивидуальным звучанием и ароматом, он выражает определённое настроение и различные способы движения.

Все цвета характеризуются разделением их на тёплые и холодные и на светлые и тёмные. Первая группа опирается на тяготение цвета к жёлтому или синему, вторая же на родство с белым или чёрным. Тёплые и светлые цвета наиболее активны, создают ощущение теплоты и развития. Холодные и тёмные выражают уход в глубину и пассивность, смерть. При сочетании цветов, выражающих различные тенденции ощущений, может возникать, например эффект шумного триумфа (светлый тёплый красный), или эффект погасших безнадёжных усилий (фиолетовый), или эффект тотального спокойствия (зелёный), или эффект отсутствия развития (серый) и т.п. Цвета «таят в себе мало исследованную, но огромную силу, которая может влиять на всё тело, на весь физический организм человека» ${ }^{9}$.

В индустрии моды цвета часто наделяют соответствующим названием, который вкупе с цветовой коммуникацией создаёт неповторимость хроматического измерения костюма, как бы подкрепляя то направление ощущений, к которым ведёт переживание цвета. Примером могут служить такие обозначения, например, как цвета «утреннего неба», «чайной розы» «спелой сливы» и т.д. «Для

Кандинский В. О духовном в искусстве. М.: Архимед, 1992. С. 41

8 Там же. С. 42.

9 Там же. С. 45. передачи настроения коллекции, которое хотел создать модельер, важнее охарактеризовать цветовую гамму, чем получить перечень используемых цветов. Представление о цветовой гамме даёт более целостное и полное впечатление от коллекции, повышает возможность определить её стилистику, найти творческие источники художника» ${ }^{10}$. Однако при огромном обилии цветовых вариаций в современной моде, каждый человек может по мере индивидуальных пристрастий выбирать тот или иной цвет. Демократизация выбора цветов предполагает огромное пространство для самовыражения, которое должно соответствовать минимум основным и, как обычно бывает, немногочисленным базовыми трендами, таким, как, к примеру, соответствие сезону (зимой предпочтителен мех, летом - более легкие материалы), времени суток (утро, ланч, вечер), особенностям мероприятия (деловая встреча, детский праздник). Для подобного рода случаев дизайнеры всегда создают определённые актуальные объекты, которые необходимы для модного соответствия.

Среди других форм выразительности важное место занимает силуэт. В моде ему, пожалуй, отводится привилегированное положение. Силуэт можно определить как проектирование на плоскости контуров человеческой фигуры в модном костюме. Собственно силуэт визуально создаёт новый модный тренд, который затем наполняется другими элементами выражения. Силуэт «заключает в себе самую сущность Моды, достигая до невыразимого «духа» и поднимаясь до возвышенности, поскольку, соединяя самые разношерстные элементы <...> представляет собой самый процесс абстрагирования; одним словом, это эстетический смысл одежды» ${ }^{11}$. Силуэт полагает некую универсальную характеристику модных тенденций, которая воспроизводится конкретно в соответствующем сезоне и заполняется всеми последующими компонентами эстетической коммуникации. Необходимо отметить, что именно современная мода, в отличие от предшествующих ей, к примеру, моды 60-х или 80-х, играет с различными формами силуэтов, а потому выбор последнего становится делом личного эстетического вкуса.

Модные силуэты строятся на основании разнообразных модификаций с базовой формой,

\footnotetext{
10 Козлова Т.В., Ильичева Е.В. Стиль в костюме XX века: учебное пособие для ВУЗов. М.: МГТУ им. А.Н. Косыгина, 2003. C. 69.

11 Барт Ролан. Система Моды: Статьи по семиотике культуры / Пер. с фр., вступ. ст. и сост. С.Н. Зенкина. М.: Изд-во им. Сабашниковых, 2003. С. 145.
} 
которая опирается на известные варианты геометрических форм; к ним относятся такие, как прямоугольник, трапеция, овал и приталенный силуэт (два соединенных вершинами треугольника). Чистых упомянутых форм в моде практически не встречается, зато их комбинирование приближается к огромнейшему числу создания возможных силуэтов, опираясь на перемещение базовых форм по фронтальной оси и различные вариации асимметрии. Как отмечает Кандинский, каждая форма наделена особым «ароматом»: «Сама форма, даже если она совершенно абстрактна и подобна геометрической, имеет свое внутреннее звучание, является духовным существом с качествами, которые идентичны с этой формой» ${ }^{12}$. Из вышесказанного, можно сказать, что силуэт несёт в себе определённую долю закодированного воздействия на эстетическое сознание, создавая фундамент для последующего наполнения эстетическими смыслами. Так, например, резкие линии силуэта создают ощущение серьёзности и напряжённости, а мягкие и округлые отсылают к домашней атмосфере уюта и спокойствия.

В основе складывания модных форм лежит структура композиции. Именно выразительная способность композиции предоставляет им большее звучание. Основное содержание композиции заключается в передаче смыслового содержания используемых актуальных объектов. Такая передача заключается в том, чтобы «сделать эти объекты носителями эмоционального содержания - произвести «перевод» их в «разряды человеческой страсти» ради выразительности изображения» ${ }^{13}$.

Так ещё известный денди Д. Браммелл XIX в. вывел композиционный закон проектирования костюма: «все объекты, объемные в верхней части и узкие в нижней, подобно перевёрнутой пирамиде, производят впечатление легкости. <..> Обратное строение, напротив, создаёт впечатление тяжести - небольшой головной убор и массивная юбка с шлейфом указывает на важную даму, в то время как обладательница крупной шляпы и укороченного платья кажется юной весёлой девушкой» ${ }^{14}$. Структура, скрывающаяся от обыденного взгляда в образной форме, опирается на

\footnotetext{
12 Кандинский В. О духовном в искусстве. М.: Архимед, 1992. С. 48.

13 Михалкович В.И., Стигнеев В.Т. Поэтика фотографии. М.: Искусство, 1990. С. 13.

14 Вайнштейн О. Денди: мода, литература, стиль жизни. 2-е изд., испр., доп. М.: Новое литературное обозрение, 2006. С. 78.
}

противопоставление центра и периферии, верха и низа, правой и левой сторон, которые являются важными атрибутами выразительности, некоего «волшебства» образа.

Среди композиционных приёмов создания модного костюма выделяют два основных: формосложение и формовычитание. Также «учитываются пропорции фигуры человека и предполагаемых форм костюма, симметричность расположения форм относительно оси симметрии человеческой фигуры» ${ }^{15}$.

Необходимо отметить, что современная мода, в отличие от прошлых столетий, предоставляет дизайнеру большее пространство выражения, задействуя в репрезентации модной одежды соответствующий антураж, который создаётся на показах и позднее копируется в рекламных изображениях. Таким образом, средства выражения задействуют не только конкретную модель, но и её звучание в симбиозе с общим фоновым содержанием, в котором используются как художественные способы выразительности (линии, цвета, формы, движение), так и приёмы построения шоу, апеллирующие к бессознательному. В качестве примера можно привести варианты показов Терри Мюглера, который, используя культурный архетип, «воссоздал на подиуме Рождество Богородицы, заполнив его монахинями и херувимами, а в финале представления модель спустилась с небес в облаке дыма и каскадах розовых конфетти» ${ }^{16}$. Иными словами, при создании актуальных модных образов, одежда играет центральную, но не основную роль, которая отдаётся целостной «живой» картине, внутри которой зритель и видит интересующий его наряд. Композиция в моде, выраженная на рекламных фотографиях (что занимает немалую часть процесса создания моды) строится по законам композиции эстетики фотографии, а композиционная структура показа мод опирается на идею создания массового шоу.

Особое место в ряду выразительных средств феномена моды занимает ритм. Вообще ритм характеризуется как периодическое повторение в пространстве и времени изоморфных объектов, связей, отношений; в модном дизайне это «чередование с определённой закономерностью элементов пластического выражения или композиционных приёмов, использованных при создании одной

\footnotetext{
15 Козлова Т.В., Ильичева Е.В. Стиль в костюме XX века: учебное пособие для ВУЗов. М.: МГТУ им. А.Н. Косыгина, 2003. C. 44.

16 Свендсен Л. Философия моды / Пер. с норв. А. Шипунова. М.: Прогресс-Традиция, 2007. С. 148.
} 


\section{Философия и культура 11(95) • 2015}

модели или коллекции» ${ }^{17}$. Ритм создаёт весомые условия для эстетического опыта, поскольку организует представленное многообразие модных объектов в единое целое и подготавливает почву для положительного эмоционального видения.

В феномене моды следует выделить три уровня проявления ритма. Во-первых, как говорилось выше, он используется как средство для выражения образа в дизайне одежды, во-вторых, является неотъемлемой частью показов коллекций, задействующих ритм движения моделей, музыку и другие элементы шоу. Третий уровень более масштабный и соотносится с модой как социокультурным феноменом, характеризующимся, с одной стороны, присутствием некой цикличности, связанной с сезонными изменениями (изменения обязательны каждый сезон), а с другой стороны, постоянным цитированием предшествующих собственных достижений, однако уже в трактовке современности. Как видим, мода представляет собой весьма пронизанный ритмическим развитием процесс. Ритм моды - это не просто повторяемость, это не некая повторяющаяся однородность, это тот ритм, о котором писали философы жизни, в частности Клагес. Он относил ритм к верховным феноменам жизни («бессознательный, космический ритм», который мы наблюдаем в эволюции растений и животных). «Все без исключения процессы органической природы являются ритмическими, но никогда не метрическими» ${ }^{18}$. Юлия Кристева также развивает понятие ритма, раскрывая его содержание в платоновском «хора» («круговым движением вечного бытия в самом себе, движением, не знающим пространственных перемен и не зависящим от перемены» ${ }^{19}$. Этот ритм как раз и характеризуется упорядоченной игрой означающих, что мы и видим в моде. Ритм работает на уровне подтверждения доверия и спокойствия. Ритм - отражение поверхностных слоев бессознательного (предпороговое состояние перехода бессознательного в сознательное). Таким образом, ритм работает на уровне бессознательного, являясь формой органического развития живой природы, и обеспечивает удовлетворение тому, кто его переживает.

Если ритм отличается периодическим повторением изоморфных элементов, то орнамент, ко-

\footnotetext{
17 Козлова Т.В., Ильичева Е.В. Стиль в костюме XХ века: учебное пособие для ВУЗов. М.: МГТУ им. А.Н. Косыгина, 2003. C. 73

18 Философский энциклопедический словарь. Ритм / Ред.сост. Е.Ф. Губский и др., 2003. С. 152.

19 Ильин И.П. Постструктурализм, деконструктивизм, постмодернизм. М.: Интрада, 1996. С. 132.
}

торый также относится к средствам визуальной выразительности в моде, характеризуется метрическим развитием его составляющих. Орнамент непосредственно задействован в дизайне одежды и выполняет более узкую функцию, в отличие от ритма. Он часто используются дизайнерами как для создания модных этнических коллекций, так и для неэтнических. Во втором случае ультрамодная одежда, «разбавленная» орнаментальными узорами, смотрится по-особому современно. Природа эстетического опыта, возникающего в результате созерцания орнаментальных изображений, уходит глубокими корнями в человеческое прошлое. Кандинский отмечает недооцененность орнаментики современными деятелями искусства, поскольку она наделена собственной внутренней жизнью и поскольку является также формой мышления, которая в современной жизни угасла, но есть все основания для её возрождения. Мир орнамента является особым миром, в котором «нет разницы между взрослыми людьми и эмбрионами и в котором они играют одинаковые общественные роли; миром, где существа с оторванными частями тела поставлены на одну доску с самостоятельно живущими носами, пальцами и пупками. Это - комбинаторика калейдоскопа, инициатором которой является не дух, а материальная случайность» ${ }^{20}$. Истоки орнамента, можно сказать, исходят из бессознательного, создавая неповторимость очарования, и перекликаясь с древним мироощущением, когда единственной судьбой были игра и случай.

В основе композиционного соотношения элементов модного образа во все времена лежали три основных направления деятельности модельеров, а именно: стилеобразование, эклектика, стилизация.

Стилеобразование - самая ценная сфера процесса создания модного образа. Создание собственного исключительного стиля - высшая цель дизайнера. Раньше эмблемой стиля служили особенные силуэт и композиция, единство художественного образа. В современной моде, в связи с появлением, с одной стороны, такого процесса формообразования, как полистилизм, а с другой, с расширением влияния моды и на фоновое измерение повседневности, стиль строится и развивается как стиль жизни с соответствующим антуражем и манерой себя преподнести. Обычно стильным называют человека, в котором идеально без возможных излишеств соединяются его внешний и внутренний облик: его одежда, обувь, мимика, голос,

20 Кандинский В. О духовном в искусстве. М.: Архимед, 1992. C. 88. 
манеры, жесты, отношение к жизни. Легендарный редактор журнала Harper's Bazaar Диана Вриланд говорила своим читателям: «Вы обязаны иметь стиль. Это поможет Вам вставать по утрам. Это образ жизни» ${ }^{21}$. Таким образом, стиль можно определить как идейное, или концептуальное, единство стилевых черт образа в широком смысле слова. Было бы огромной ошибкой для современного модельера рассматривать костюм без его динамики на теле человека. Жесты и позы становятся важным элементом стилеобразования, поскольку они открывают «путь к пониманию культурного кода и эмоциональной жизни той или иной эпохи. Жест является показателем и средством социальной дифференциации общества» ${ }^{22}$. Таким образом, в современной моде понятие стиля претерпевает изменения и наделяется новыми смыслами, связанными с моделью поведения и репрезентации собственной жизни. Теперь для создания уникального стиля необходимо создавать некие виртуальные миры, которые в соответствии с собственными эстетическими предпочтениями будут избираться адептами моды. Дизайнер как бы вплетает свой костюм в подобного рода символические поля. В современной моде новейшим мэйн-стримом становится процесс стилеобразования, идущий от самих потребителей и уже сложно определить имя создателя стиля: «тон стал задавать покупатель - именно он сам определяет, какую одежду хочет носить, какой образ желает принять; его эстетические предпочтения становятся законом для производителей. Можно сказать, что вместо прежних «диктаторов моды» появился новый, не менее могущественный диктатор - потребитель» ${ }^{23}$.

Стилеобразование всегда граничит с эклектикой в силу сложности поисков нового стиля и в процессе попыток его создания. Эклектика - это соединение в одном образе нескольких разнообразных элементов без учёта их гармонического и функционального сочетания. Однако этот принцип в современной моде становится особым самостоятельным явлением, которое совершенно не воспринимается как нечто негативное и которое, наоборот, начинает приближаться в синонимичном ряду к самому понятию стиля. Такой поворот событий имеет глубокие корни истории формиро-

\footnotetext{
21 Левин Дж. Harper's Bazaar. Великолепный стиль. М.: ЭКСМО, 2008. С. 7.

22 Козлова Т.В., Ильичева Е.В. Стиль в костюме ХХ века: учебное пособие для ВУЗов. М.: МГТУ им. А.Н. Косыгина, 2003. C. 43.

23 Полях Е.А. Постмодернизм и дизайн // Вестник московского университета. Серия 7.Философия. 1998. № 5. С. 89.
}

вания коллективного представления о гармонии. Новое видение прекрасного в современном мире ещё описал В.В. Кандинский: «борьба тонов, утраченное равновесие, рушащиеся «принципы», внезапный барабанный бой, великие вопросы, видимо бесцельные стремления, видимо беспорядочный натиск и тоска, разбитые оковы и цепи, соединяющие воедино противоположности и противоречия - такова наша гармония» ${ }^{24}$. Чтобы создать наиболее подходящий современный образ, необходимо уравновесить два или три совершенно противоположных используемых стиля. Например, журналы мод рекомендуют женственную блузку «разбавить» рок-н-ролльными джинсами, а длинный строгий пиджак совместить с летними шортами. Сочетанием изысканности и китча отличаются многие работы дизайнеров. Современная «гармония основана главным образом на принципе контраста <...> Но наш контраст есть контраст внутренний, который стоит обособленно и исключает всякую помощь других гармонизирующих принципов. Сегодня они излишни и только мешают!» ${ }^{25}$.

Другим принципом создания модных образов выступает принцип стилизации. Этот приём характеризуется двумя значениями. В первом случае стилизация представляет собой цитирование целого или части исторически или этнически сложившегося стиля; во втором случае речь идёт о создании нового современного образа на основе стилевого первоисточника. В обоих вариантах могут быть использованы приёмы объединения, нарочитого утрирования исходных стилевых черт, деформация естественной человеческой формы. Стилизация также представляет интерес в области эстетики выразительности, поскольку расширяет пространство для воображения и индивидуального творчества.

Таким образом, мы видим, что в моде существует особого рода способы и формы выразительности, наделённые эстетическим содержанием, которые фиксируются исключительно эмоционально. В этом случае нам следует говорить о формировании более чётких границ понятия смысла моды, которое столь часто и безысходно ищут обыватели, журналисты, социологи. Подобного рода смысловые коды, передаваемые с помощью эстетической коммуникации, характеризуют не только узкую сферу деятельности дизайнеров, но и создают специфическую форму новой модной реальности.

\footnotetext{
24 Кандинский В. О духовном в искусстве. М.: Архимед, 1992. C. 82.

25 Там же. С. 84.
} 


\section{Философия и культура 11(95) • 2015}

Список литературы:

1. Барт Ролан. Система Моды. Статьи по семиотике культуры / Пер. с фр., вступ. ст. и сост. С.Н. Зенкина. М.: Изд-во им. Сабашниковых, 2003.

2. Бодрийяр Ж. Символический обмен и смерть. 2-е изд. М.: Добросвет, КДУ, 2006.

3. Вайнштейн О. Денди: мода, литература, стиль жизни. 2-е изд., испр., доп. М.: Новое литературное обозрение, 2006.

4. Гофман А.Б. Мода и люди. Новая теория моды и модного поведения. М., 1994.

5. Гофман А.Б. Мода и обычай // Рубеж: альманах социальных исследований. 1992. Вып. 3.

6. Дзикевич С.А. Эстетика Рекламы: учебное пособие. М.: Гардарики, 2004.

7. Ильин И.П. Постструктурализм, деконструктивизм, постмодернизм. М.: Интрада, 1996.

8. Юнийа Кавамура. Теория и практика создания моды. М.: 000 «Гревцов Паблишер», 2009.

9. Кандинский В. О духовном в искусстве. М.: Архимед, 1992.

10. Козлова Т.В., Ильичева Е.В. Стиль в костюме ХХ века: учебное пособие для ВУЗов. М.: МГТУ им. А.Н. Косыгина, 2003.

11. Коммуникативные проекты в контексте современной теории моды: материалы межвузовского семинара в рамках проекта «Коммуникация. Культура. Мода». М.: РГГУ, 2005.

12. Кузнецова Т.В. Феномен моды: эстетика и диалектика // Философские науки. 1991. № 6.

13. Кузнецова Т.В. Феномен моды: эстетические аспекты // ОМЭК І. Эстетика: прошлое, настоящее и будущее. М.: МГУ, 2005.

14. Левин Дж. Harper's Bazaar. Великолепный стиль. М.: ЭКСМО, 2008.

15. Михалкович В.И., Стигнеев В.Т. Поэтика фотографии. М.: Искусство, 1990.

16. Полях Е.А. Постмодернизм и дизайн // Вестник московского университета. Серия 7. Философия. 1998. № 5.

17. Свендсен Л. Философия моды / Пер. с норв. А. Шипунова. М.: Прогресс-Традиция, 2007.

18. Федорова А.В. Проблема ритма в эстетической теории // Вестник Московского университета. Серия 7. Философия. 2002. № 1.

19. Философский энциклопедический словарь. Ритм / Ред.-сост. Е.Ф. Губский и др. М., 2003.

20. Эко У. Отсутствующая структура. Введение в семиологию. СПб.: ТОО ТК «Петрополис», 1998.

21. Элиас Н. О процессе цивилизации: Социогенетические и психогенетические исследования. М., 2001.

\section{References (transliteration):}

1. Bart Rolan. Sistema Mody. Stat'i po semiotike kul'tury / Per. s fr., vstup. st. i sost. S.N. Zenkina. M.: Izd-vo im. Sabashnikovykh, 2003.

2. Bodriiyar Zh. Simvolicheskii obmen i smert'. 2-e izd. M.: Dobrosvet, KDU, 2006.

3. Vainshtein O. Dendi: moda, literatura, stil' zhizni. 2-e izd., ispr., dop. M.: Novoe literaturnoe obozrenie, 2006.

4. Gofman A.B. Moda i lyudi. Novaya teoriya mody i modnogo povedeniya. M., 1994.

5. Gofman A.B. Moda i obychai // Rubezh: al'manakh sotsial'nykh issledovanii. 1992. Vyp. 3.

6. Dzikevich S.A. Estetika Reklamy: uchebnoe posobie. M.: Gardariki, 2004.

7. Il'in I.P. Poststrukturalizm, dekonstruktivizm, postmodernizm. M.: Intrada, 1996.

8. Yuniia Kavamura. Teoriya i praktika sozdaniya mody. M.: 000 «Grevtsov Pablisher», 2009.

9. V. Kandinskii. 0 dukhovnom v iskusstve. M.: Arkhimed, 1992.

10. Kozlova T.V., Il'icheva E.V. Stil' v kostyume XX veka: uchebnoe posobie dlya VUZov. M.: MGTU im. A.N. Kosygina, 2003.

11. Kommunikativnye proekty v kontekste sovremennoi teorii mody: materialy mezhvuzovskogo seminara v ramkakh proekta «Kommunikatsiya. Kul'tura. Moda». M.: RGGU, 2005.

12. Kuznetsova T.V. Fenomen mody: estetika i dialektika // Filosofskie nauki. 1991. № 6.

13. Kuznetsova T.V. Fenomen mody: esteticheskie aspekty // OMEK I. Estetika: proshloe, nastoyashchee i budushchee. M.: MGU, 2005.

14. Levin Dzh. Harper's Bazaar. Velikolepnyi stil'. M.: EKSMO, 2008.

15. Mikhalkovich V.I., Stigneev V.T. Poetika fotografii. M.: Iskusstvo, 1990.

16. Polyakh E.A. Postmodernizm i dizain // Vestnik moskovskogo universiteta. Seriya 7. Filosofiya. 1998. № 5.

17. Svendsen L. Filosofiya mody / Per. s norv. A. Shipunova. M.: Progress-Traditsiya, 2007.

18. Fedorova A.V. Problema ritma v esteticheskoi teorii // Vestnik Moskovskogo universiteta. Seriya 7. Filosofiya. 2002 . № 1.

19. Filosofskii entsiklopedicheskii slovar'. Ritm / Red.-sost. E.F. Gubskii i dr. M., 2003.

20. Eko U. Otsutstvuyushchaya struktura. Vvedenie v semiologiyu. SPb.: TOO TK «Petropolis», 1998.

21. Elias N. O protsesse tsivilizatsii: Sotsiogeneticheskie i psikhogeneticheskie issledovaniya. M., 2001. 